\title{
A benchmarking project of physiotherapy in Australian and New Zealand adult major trauma services
}

\author{
Sara Calthorpe BSc, (Hons) Physio \\ Department of Physiotherapy, Alfred Health and La Trobe University, Melbourne, Victoria, Australia
}

Lara A. Kimmel BPhysio, GradDipClinEpi, PhD

Department of Physiotherapy, Alfred Health and Department of Epidemiology and Preventive Medicine, Monash University, Melbourne, Victoria, Australia.

Melissa J. Webb BPhysio, MHlthSc

Department of Physiotherapy, Alfred Health, Melbourne, Victoria, Australia and Notre Dame University, Fremantle, WA, Australia

Anne E. Holland BAppSc, (Physio), PhD

Department of Physiotherapy, Alfred Health and Discipline of Physiotherapy La Trobe University, Melbourne, Victoria, Australia.

\section{ABSTRACT}

Traumatic injury places a great burden on individuals and society. As mortality plateaus in mature trauma systems, there is an increasing shift towards understanding patients' morbidity and functional outcomes. Physiotherapy plays a key role in recovery after traumatic injury, but little is currently known about its role in the acute hospital setting for trauma patients. This study aimed to document physiotherapy service structure and practice in adult major trauma services (MTS) across Australia and New Zealand. A survey was distributed electronically to physiotherapists working within designated MTS ( $n=25)$, achieving a $92 \%$ response rate $(n=23)$. Physiotherapy service delivery, expertise and availability varied greatly. Only seven sites (30\%) had a dedicated trauma physiotherapist with this showing a trend towards an association with major trauma admissions (provided by the Australian Trauma Registry; $p=0.07)$. Only eight (35\%) had blanket referral systems for physiotherapy review, which was significantly associated with having a dedicated specialised physiotherapist $(p=0.015)$. Most ran a five day/week service for all patients with priority cover over the weekends $(78 \% n=18)$. Future research should explore the benefits of specialised trauma physiotherapy roles in optimising patient outcomes in order to standardise this across all trauma centres in Australia and New Zealand.

\section{Calthorpe S, Kimmel L, Webb M, Holland A (2016) A Benchmarking Project of Physiotherapy in Australian and New Zealand Adult Major Trauma Services. New Zealand Journal of Physiotherapy 44(3): 148-156. doi: 10.15619/NZJP/44.3.04}

Key words: Physiotherapy, Wounds and injuries, Physical therapy modalities, Multiple trauma, Benchmarking.

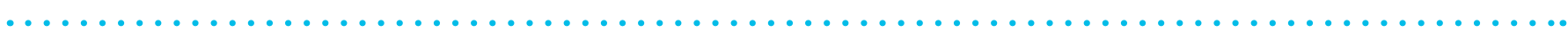

\section{INTRODUCTION}

Traumatic injury is the most common cause of death in those aged less than 45 years in Australia and New Zealand (NZ) and the fourth highest regardless of age (Australian Institute of Health and Welfare 2014, Ministry of Health New Zealand 2006, 2015). Organised systems of trauma care that exist in both countries have been shown to reduce mortality (Ashley et al 2015, Cameron et al 2008, Gabbe et al 2011) and central to this system design is the categorisation of hospitals to provide designated levels of trauma care (from Level I to Level IV). Requirements for Level I trauma centres include defined hospital infrastructure such as a helipad landing site and access to emergency operating theatres 24 hours a day, as well as specified healthcare professionals. The professionals included are pre-hospital, specialist medical and nursing staff, with little mention of allied health or rehabilitation team members such as physiotherapy. Most designated Australian and NZ major trauma services (MTS) fulfil Level I or II criteria.

As these systems mature, there is an increasing shift towards measuring the quality of life for survivors and their morbidity over time (Cameron et al 2006). Care at MTS has been shown to improve functional outcomes (Gabbe et al 2016, MacKenzie et al 2008, Nirula and Brasel 2006), but the reasons for this are unknown. It has been suggested that this may, in part, relate to greater clinical expertise, experience and staffing levels within allied health (Gabbe et al 2012), whose interventions are specifically focused on this aspect of patient recovery.

Physiotherapists are an integral part of the trauma team. Their input is primarily concerned with the resolution or reduction of impairments and disabilities and the promotion of mobility, functional ability and quality of life through examination, evaluation, diagnosis, and physical intervention (Calthorpe et al 2014). Previous research has shown early physiotherapy intervention can improve early function after hip fracture (Kimmel et al 2016a) or admission following trauma (Calthorpe et al 2014). It has also been shown to reduce hospital length of stay (LOS) (Calthorpe et al 2014; Kimmel et al 2012; Kimmel et al 2016a). Early functional mobility was measured using the modified lowa level of assistance score (mILOA), which has been shown to be reliable and valid in an acute hospital population (Kimmel et al 2016b). The implications of this emerging evidence relating to trauma care and health care systems could be profound. With a modest investment in acute inpatient physiotherapy services, it may be possible to reduce overall costs and improve patient outcomes. However, it is important to engage physiotherapists working within MTS to participate in comparative benchmarking work as a step towards 
understanding optimal physiotherapy service delivery before commencing clinical practice benchmarking (Ellis 2006).

In Australia and NZ, little is currently known about the structure of physiotherapy services to trauma patients. In Canada, comparative work found great variability of physiotherapy service structure within their MTS but key findings included a five day a week full physiotherapy service to trauma patients with priority-only coverage at weekends. Additionally, the majority worked within a separate physiotherapy department structure, where management decisions and quality assurance focused on the best interests of the physiotherapy department as a whole rather than necessarily being patient or unit specific (Fisher et al 2012).

The primary purpose of this study was to document current physiotherapy service structure and practice in the adult MTS across Australia and NZ. Additionally we aimed to ascertain what factors are associated with the amount and type of physiotherapy intervention to trauma patients.

\section{METHODS}

A purpose-designed survey was undertaken to collect information regarding the characteristics of physiotherapy service provision at MTS in Australia and New Zealand. This information was matched, where available, with quantitative information describing MTS admission numbers, LOS and discharge destination. The project was approved by the Alfred Research and Ethics committee as a low risk project (579/14).

The Australian adult MTS were identified through the inaugural report published by the Australian Trauma Registry (Alfred Health 2014) and the NZ adult MTS from a publication regarding their systems (Paice 2007). Twenty-five sites were identified in total; 19 in Australia and six in NZ.

Since no validated tool existed for benchmarking trauma physiotherapy services, a survey was designed using 16 open and closed ended questions. This was divided into three sections: trauma service model of care, trauma physiotherapy service provision and patient scenarios. The scenarios were included to help better understand the assessments and interventions physiotherapists complete with specific patient groups. These scenarios reflected the diverse nature of trauma patients from young to older adults, with varying severity of injury and pre-existing comorbidities. All involved at least two separate injuries and respondents were asked what input they would give to the patient on a defined day in their hospital stay. The initial version was pilot-tested by two senior physiotherapists who worked in Australian adult MTS and one physiotherapist who worked in a Victorian metropolitan trauma service. Based on their feedback, the survey was altered and finalised (Appendix).

The physiotherapy managers were contacted via email and requested to provide the contact details for the most senior physiotherapist who managed the trauma patients at their institution. The survey was distributed electronically via SurveyMonkey (SurveyMonkey Inc.) and included a cover letter inviting participation. Participants were informed that completion of the survey would indicate their consent. Where required, reminder emails for non-responders were distributed.
To receive the most accurate information with regards to major trauma patient admissions, LOS and discharge destination at each MTS, the Australian Trauma Registry (ATR) was used. This registry was developed as part of the Australian Trauma Quality Improvement Program (AusTQIP), a collaboration of the 26 designated Australian MTS (adult and paediatric), with the aim to provide an evidence base for trauma quality improvement and development of performance indicators. The ATR included the bi-national minimum dataset (BMDS) developed by the collaborative Australian and New Zealand National Trauma Registry Consortium (Palmer et al 2013). Although NZ were involved in the development of the BMDS, NZ MTS data were not included in the ATR. Request to access the data items listed using the ATR data access policy was undertaken with permission received in writing from the ATR manager. Data items extracted were: major trauma patient admission numbers, acute hospital length of stay and discharge destination for the period 2010- 2012. Provided data were coded but were reidentifiable to allow them to be linked to the survey information where possible.

\section{Statistical Analysis}

Survey results and ATR data items (where available) were combined together into a spreadsheet. Numerical data were analysed using SPSS version 22.0 for Windows (IBM Chicago, IL). Continuous data were presented as means and standard deviations or medians and interquartile ranges for data not normally distributed. To explore any relationships between major trauma patient admission numbers, LOS and discharge destination with trauma unit and physiotherapy service structure, either an independent samples t-test or a nonparametric Mann-Whitney $U$ test was performed. To explore relationships between trauma and physiotherapy service structure, a Chi-squared test was performed. Open-ended responses were grouped according to themes and the responses to case scenarios were reported as percentages.

\section{RESULTS}

Twenty five questionnaires were distributed with a response rate of $92 \%(n=23)$. Of these, 18 were from Australia and five from NZ. For the ATR data items requested, 70\% $(n=16 / 23)$ had complete data available, one site had incomplete data and two sites had not contributed any data to the ATR at the time of the study. Overall, complete survey and ATR data were available from 15 of the 25 sites (60\%). All available data were used for the analysis.

Table 1 summarises the responses to key questions regarding trauma unit and physiotherapy service. Only five (22\%) of the 23 respondents worked in a hospital with a dedicated trauma bedcard; that is, the ability to admit a trauma patient and continue their care throughout their acute hospital stay until discharge. In all other MTS, trauma patients were admitted under sub-specialty units such as Neurosurgery, Orthopaedics and General Surgery. Of these sites without a dedicated trauma bedcard, three described a "trauma service" that helped coordinate all trauma patients' care across the hospital. Seven of the 23 sites (30\%) had a dedicated trauma physiotherapist defined as being either allocated to the trauma unit or identified as the key physiotherapist who managed trauma patients. 
Table 1: Trauma service and physiotherapy service characteristics

\begin{tabular}{lc}
\hline Characteristic & $\begin{array}{c}\text { Number of MTS } \\
\mathbf{n = 2 3}(\%)\end{array}$ \\
\hline Dedicated trauma bedcard & $5(22)$ \\
\hline Dedicated trauma physiotherapist & $7(30)$ \\
\hline $\begin{array}{l}\text { Blanket referral* for physiotherapy } \\
\text { review }\end{array}$ & $8(35)$ \\
\hline $\begin{array}{l}\text { Out of business hours physiotherapy } \\
\text { service }\end{array}$ & $3(13)$ \\
\hline $\begin{array}{l}\text { On-call physiotherapy service } \\
\text { Weekend physiotherapy service for } \\
\text { prioritised patients only }\end{array}$ & $18(78)$ \\
$\begin{array}{l}\text { Weekend physiotherapy service for all } \\
\text { patients }\end{array}$ & $5(22)$ \\
\hline
\end{tabular}

Notes: MTS, Major trauma service.

*Blanket referral is where all trauma patients are seen (referral not needed)

Of those sites with a trauma bedcard, $60 \%(n=3 / 5)$ also had a dedicated trauma physiotherapist, whereas of those sites without a trauma bedcard $(n=18 / 23)$, only $22 \%(n=4 / 18)$ had a dedicated trauma physiotherapist $(p=0.10)$. Of those sites with a dedicated trauma physiotherapist $(n=7 / 23)$, five $(71 \%)$ physiotherapists were full-time senior specialists supported by mainly rotating seniors and juniors, many of whom worked within trauma in a part-time capacity only. These specialist trauma physiotherapists reviewed trauma patients in various locations across the hospital including: the emergency department (ED), intensive care unit (ICU), wards and outpatient clinic. At the other 16 sites without a dedicated trauma physiotherapist, trauma patients were seen by an array of other specialised and rotational physiotherapists of varying levels of seniority, including but not limited to ICU, cardiothoracic, plastics, orthopaedics, neurosurgery, ED, burns, general surgery, spinal and rehabilitation.

The 2012 ATR data revealed a wide range of major trauma patient admission numbers across Australian MTS with a median of 342 admissions per year ( $n=17$ sites, IQR 177-385 admissions) and a mean length of stay of 9.3 days ( $n=17$, SD 1.9 days). On average, the percentage of major trauma patients discharged home was $52 \%(n=16$, SD 10.2) and to rehabilitation was $31 \%$ $(n=16, S D$ 9.7). Sites with greater numbers of major trauma patient admissions tended to be more likely to have a dedicated trauma physiotherapist (median 541 vs 240 admissions, $p=0.07$ ). Similarly those with greater admission numbers tended to be more likely to have a dedicated trauma bedcard (median 774 vs 314 admissions, $p=0.13$ ).

Only $35 \%(n=8 / 23)$ of respondents reported their site had a blanket referral for physiotherapy review of trauma patients. This involved a systematic review of all trauma admissions by a physiotherapist to establish current needs, identify any potential problems and implement an early therapy regime as required. Those sites with a dedicated trauma physiotherapist $(n=7 / 23)$ were significantly more likely to have a blanket referral for physiotherapy review $(p=0.02)$. All sites $(n=23)$ provided a physiotherapy service to trauma patients from Monday-Friday during business hours (8am - 4.30pm), with three sites also providing extended later hours coverage until around 8pm every weekday only. Eight sites (35\%) also provided an "oncall" service. This service was identified as being for high risk patients with a deteriorating respiratory issue where further physiotherapy input would be beneficial out of usual business hours. This service was available to all patients within the MTS hospital, not just trauma patients. One site also included discharges and priority casting within their "on-call" service. One further site reported no structured "on-call" system, but identified they did provide an out of hours service on a needs basis for a defined group of cervical/upper thoracic spinal cord injured patients. With regards to weekend physiotherapy service provision, five sites (22\%) provided a full business hours service, with all other sites providing a reduced/ prioritised service only.

Only three sites (13\%) reported collecting any standardised outcome measures for physiotherapy interventions. These included the burns specific health scale or BSHS (Blades et al 1982); the modified lowa level of assistance score or mILOA (Kimmel et al 2016b) and the de Morton Mobility Index (de Morton et al 2008). Time points for administering these measures to trauma patients varied.

Trauma physiotherapy specific clinical guidelines, assessment tools, pathways and competencies were used within $48 \%$ $(n=11 / 23)$ of the sites. Of the respondents, $74 \%(n=17 / 23)$ reported they run trauma specific education sessions for physiotherapy staff, usually as part of their physiotherapy department in-service training. One site also reported they run an annual trauma lecture series and basic trauma day for physiotherapists available to both internal and external staff. Some physiotherapists also attended trauma team education sessions, along with other trauma activities as detailed in table two.

\section{Table 2: Physiotherapy attendance at trauma team activities}

\begin{tabular}{lc}
\hline Trauma team activity & $\begin{array}{c}\text { Number of MTS where } \\
\text { physiotherapists attends } \\
\mathbf{n}=\mathbf{2 2}(\%)\end{array}$ \\
\hline Handovers & $10(45)$ \\
\hline Ward rounds & $9(41)$ \\
\hline Unit meetings & $12(55)$ \\
\hline Unit audits & $3(14)$ \\
\hline X-ray meetings & $7(32)$ \\
\hline Education sessions & $12(55)$ \\
\hline No attendance at any activities & $3(14)$ \\
\hline
\end{tabular}

Notes: MTS, Major trauma service. 
Just over a quarter of respondents $(n=6 / 23)$ reported their physiotherapy staff were involved in research related to trauma patients, although $87 \%(n=20 / 23)$ were interested in being part of future collaborative physiotherapy research. There was also keen interest in being part of a trauma network aimed at supporting and sharing knowledge and skills for those working with trauma patients $(91 \%, n=21 / 23)$.

\section{Patient Scenarios}

Responses to the four patient case studies are detailed in table three, with full details of each case listed in the survey (Appendix). At all but one site, all patient cases would have been seen by physiotherapy on a weekday, but weekend input varied case by case from being seen at only $52 \%$ up to $100 \%$ of sites. There was consensus around some assessments and interventions performed, particularly with regards to musculoskeletal assessment and mobilisation, exercises and discharge planning which were completed by at least $87 \%$ of physiotherapists across the cases. Other assessments and intervention appeared to be more varied. Several physiotherapists reported that their intervention would depend on physical assessment findings. Time spent on all activities varied greatly (range 0 minutes - 25 minutes).

\section{DISCUSSION}

This study shows that there is a great variation of physiotherapy service delivery, expertise and availability within Australian and NZ adult MTS. Sites with more major trauma admissions tended to be more likely to have a dedicated trauma physiotherapist. Specific case scenarios also highlighted the varied assessment and intervention trauma patients receive across the different sites. Physiotherapists' participation in trauma team activities, trauma specific education and trauma related research also differed, although interest in collaborative research work and a supportive trauma network was high.

The variability in service provision described in this study is similar to that found in 2012 within Canadian MTS (Fisher et al 2012). These authors' research focused on models of service delivery in relation to specific hospital management structures and physiotherapy patient caseload numbers, particularly examining how the state of Ontario compared to the rest of Canada. However, comparison can be made around physiotherapy service delivery. In Canada, 89\% ( $n=17 / 19)$ of their MTS ran a physiotherapy service five days/week with cover to priority patients only over the weekend which was similar to our finding of $78 \%(n=18 / 23)$ of sites providing this structure of service delivery. Further details of the physiotherapy service delivery in Canada with regards to referral process and specialisation however were not examined, so broader comparisons are limited.

In the absence of any established guidelines around optimal physiotherapy service delivery within MTS, it is not surprising that services varied across sites. Only the sites with a blanket referral for physiotherapy review (35\% of sites) ensured that all trauma patients would have a physiotherapy assessment. Elsewhere, input relied on a referral, or was dependent on patient admission location or medical team allocation. Combined with the fact that a full physiotherapy service only occurred on weekdays and not weekends at the majority of sites ( $n=18 / 23,78 \%)$, it is likely that physiotherapy input for patients would often be inconsistent, even within each individual MTS. One initiative that has been shown to increase physiotherapy referral rates and reduce time to physiotherapy assessment in an Australian MTS is the addition of a trauma case manager to the trauma team (Curtis et al 2006). However, it could be argued that even this referral process is not as effective as a blanket physiotherapy referral given only $55 \%$ of all trauma patients in that study received any physiotherapy and not until a median time point of 1.5 days into their hospital stay (Curtis et al 2006). Given early and more intensive physiotherapy has been shown to improve functional independence (Calthorpe et al 2014, Khan et al 2012) and reduce length of stay (Kimmel et al 2012, Pendleton et al 2007), a more consistent approach to referrals and staffing may improve patient and organisational outcomes.

Despite the presence of an admitting trauma bedcard being regarded as essential in MTS care (Royal Australasian College of Surgeons 2014), only $22 \%$ of centres fulfilled this criterion. A potential flow on effect of not having a trauma bedcard or admitting service is that trauma patients may not always be cared for in a specialist trauma ward or unit, but rather be "outliers" on other specialist wards where nursing and allied health staff may be unfamiliar with their management and access to their medical team may be less frequent (Civil 2005).

\section{Table 3: Patient scenarios}

\begin{tabular}{lllllllll}
\hline $\begin{array}{l}\text { Case } \\
\text { Scenario }\end{array}$ & $\begin{array}{l}\text { Physiotherapy input } \\
\text { weekday/weekend } \\
\mathbf{n}(\%)\end{array}$ & $\begin{array}{l}\text { Neurological } \\
\text { assessment } \\
\mathbf{n}(\%)\end{array}$ & $\begin{array}{l}\text { Musculoskeletal } \\
\text { assessment } \\
\mathbf{n}(\%)\end{array}$ & $\begin{array}{l}\text { Respiratory } \\
\text { assessment } \\
\mathbf{n}(\%)\end{array}$ & $\begin{array}{l}\text { Exercises } \\
\mathbf{n}(\%)\end{array}$ & $\begin{array}{l}\text { Mobilisation } \\
\mathbf{n}(\%)\end{array}$ & $\begin{array}{l}\text { Respiratory } \\
\text { intervention } \\
\mathbf{n}(\%)\end{array}$ & $\begin{array}{l}\text { Discharge } \\
\text { planning } \\
\mathbf{n}(\%)\end{array}$ \\
\hline Case 1 & $22(96) / 15(65)$ & $18(78)$ & $21(91)$ & $13(57)$ & $16(70)$ & $22(96)$ & $8(35)$ & $22(96)$ \\
\hline Case 2 & $23(100) / 21(91)$ & $11(48)$ & $22(96)$ & $23(100)$ & $21(91)$ & $23(100)$ & $23(100)$ & $21(91)$ \\
\hline Case 3 & $23(100) / 12(52)$ & $8(35)$ & $23(100)$ & $11(48)$ & $23(100)$ & $23(100)$ & $6(26)$ & $21(94)$ \\
\hline Case 4 & $23(100) / 23(100)$ & $6(26)$ & $20(87)$ & $23(100)$ & $20(87)$ & $23(100)$ & $23(100)$ & $20(87)$ \\
\hline
\end{tabular}

Note: All percentages calculated from the $n=23$ responses.

Case 1: 75 year old female two days post fall with C6 and wrist fracture just cleared to mobilise.

Case 2: 25 year old male post motor vehicle accident, day one post laparotomy and ankle fixation with eight fractured ribs and smoking history.

Case 3: 50 year old female four days post motorbike accident with left femoral nail and fixation of L3 fracture who has so far managed only to sit out of bed.

Case 4: 80 year old male three days post fall at home with right pubic rami and five fractured ribs with flail and intercostal catheter with secretion retention and increasing oxygen requirements 
Sub-optimal nursing care has been demonstrated with trauma patients "out-lying" in three UK hospitals with "positively dangerous" potential implications identified (Lloyd et al 2005). In this survey, only seven (30\%) sites had a dedicated trauma physiotherapist, with just five of these reported as senior permanent full-time positions; not surprisingly these tended to be sites with more trauma admissions. In other centres, patients were seen by an array of specialist and rotational physiotherapists with varying levels of experience. It is therefore possible that similar effects may occur for physiotherapy care. Although such research has not been undertaken in a trauma specific context, an association between organisational structure and clinical outcomes has been demonstrated in other patient populations and provides support for specialist health clinicians (Strasser et al 2005). The MTS should consider this in the context of physiotherapy service provision and recognise trauma physiotherapy as a defined speciality. University postgraduate qualifications are emerging in this area for allied health clinicians, which may assist with this process, although further evaluation to optimise service delivery and patient outcomes must also be a priority. Participation in trauma team activities was low, presumably due to few dedicated trauma physiotherapists and varied trauma and physiotherapy team service structure. Of particular note is that physiotherapists attended ward rounds at less than $50 \%$ of the sites, despite research that shows their participation in this activity can reduce trauma patient hospital length of stay (Dutton et al 2003).

Only three respondents reported using any objective measures of treatment outcome with their patients. This may be due to the paucity of evidence around the best outcome measure for use in this diverse population. Recently the mILOA has been shown to be responsive, reliable and valid in patients following trauma in the acute setting (Calthorpe et al 2014, Kimmel et al 2016b). Additionally, the Functional Independence Score (FIM) motor subscore at acute hospital discharge has been shown to be a predictor of 6 month functional outcome and return to work (Gabbe et al 2008), although its ease of use in the acute hospital and its limitations in the younger trauma patient are unknown.

The case scenarios provided some information around current usual physiotherapy practice with regards to assessments and interventions performed in specific common trauma patient case examples. Despite some consensus around assessment and intervention requirements, variability in practice remained evident. This demonstrates the need for stronger evidence to guide physiotherapy practice for trauma patients, although currently only $26 \%$ are involved in any such research. This reflects a need to build capacity in trauma physiotherapy research, the interest for which was found to be high with $87 \%$ interested in collaborative work and $91 \%$ interested in a trauma network to support allied health clinicians.

\section{Limitations}

Due to the variation in physiotherapy service structure to trauma patients across Australia and NZ, it was not always possible to identify one key trauma physiotherapist at each site and the survey may have been completed by more than one physiotherapist working in various areas. As a result, the survey responses may be influenced by the speciality of the physiotherapist answering the questions. Years of experience or expertise specifically in the area of trauma were also not sought in the questionnaire. As we only accessed the data items from the ATR, these were not available for any of the NZ sites, limiting our analysis of these factors and their relationship to service delivery. Interpretation of the case scenarios may have been influenced by limited details provided, so it may have been difficult for physiotherapists to accurately report their treatment approach without more specific information on assessment findings.

\section{CONCLUSION}

This study is the first to provide information around current physiotherapy practice within Australian and NZ MTS. Most MTS do not have an admitting trauma bedcard and do not have a dedicated trauma team co-ordinating their care beyond the first 24 hours of their admission. Physiotherapy service and structure at the MTS was related to major trauma patient admission numbers, with higher volume sites tending to be more likely to have a dedicated trauma physiotherapist. This factor also impacted on trauma patient access to physiotherapy, with those sites also more likely to have blanket referral for physiotherapy.

The variability documented in this study highlights the need for robust evidence to underpin trauma physiotherapy and service delivery models. Future research should focus on the role of the trauma physiotherapy specialist within a trauma team in an attempt to ensure consistent high quality care, optimal patient outcomes and organisational efficiency.

\section{KEY POINTS}

1. There is great variation of physiotherapy service delivery, expertise and availability within Australian and NZ adult MTS.

2. Sites with higher numbers of major trauma patient admissions are more likely to have a dedicated trauma physiotherapist and a blanket referral system for physiotherapy review.

3. Most sites ran a five day/week physiotherapy service for all trauma patients with priority-only cover during the weekends.

4. Future research should explore the benefits of specialised trauma physiotherapy roles in optimising patient outcomes.

\section{PERMISSIONS}

Ethics approval for this study was obtained from the Alfred Health Human Research Ethics as a low risk project (579/14).

\section{DISCLOSURES}

This study was supported in part by an allied health research grant from the Alfred Hospital.

The authors declare no conflicts of interest. 


\section{ACKNOWLEDGEMENTS}

We thank all the Australian Trauma Quality Improvement Program Collaborators for the provision of Australian Trauma Registry summary data. Provision of this data in no way constitutes endorsement by the ATR or its collaborators of any conclusion of the authors. We also thank the physiotherapists who participated in completing the surveys.

\section{ADDRESS FOR CORRESPONDENCE}

Sara Calthorpe, Department of Physiotherapy, Alfred Health, Commercial Road, Prahran, Melbourne, Victoria 3181. Telephone: +61390763450. Email: s.calthorpe@alfred.org.au.

\section{REFERENCES}

Alfred Health (2014) Caring for the severely injured in Australia: Inaugural report of the Australian Trauma Registry 2010 to 2012. Melbourne, Victoria.

Ashley DW, Pracht EE, Medeiros RS, Atkins EV, NeSmith EG, Johns TJ, Nicholas J M (2015) An analysis of the effectiveness of a state trauma system: treatment at designated trauma centers is associated with an increased probability of survival. Journal of Trauma and Acute Care Surgery 78(4): 706-712; discussion 712-704. doi:10.1097/TA.0000000000000585.

Australian Institute of Health and Welfare (2014) Australia's health 2014 (AlHW cat. no. AUS 178).

Blades B, Mellis N, Munster AM (1982) A burn specific health scale. Journal of Trauma 22(10): 872-875.

Calthorpe S, Barber EA, Holland AE, Kimmel L, Webb MJ, Hodgson C, Gruen RL (2014) An intensive physiotherapy program improves mobility for trauma patients. Journal of Trauma and Acute Care Surgery 76(1): 101106. doi:10.1097/TA.0b013e3182ab07c5

Cameron PA, Gabbe BJ, Cooper DJ, Walker T, Judson R, McNeil J (2008) A statewide system of trauma care in Victoria: effect on patient survival. Medical Journal of Australia 189(10): 546-550.

Cameron PA, Gabbe BJ, McNeil JJ (2006) The importance of quality of survival as an outcome measure for an integrated trauma system. Injury 37(12): 1178-1184. doi:10.1016/j.injury.2006.07.015.

Civil ID (2005) Good trauma care doesn't happen by accident. Injury 36(6): 689-690. doi:10.1016/j.injury.2005.04.001.

Curtis K, Zou Y, Morris R, Black D (2006) Trauma case management: improving patient outcomes. Injury 37(7): 626-632. doi:10.1016/j. injury.2006.02.006

de Morton NA, Davidson M, Keating JL (2008) The de Morton Mobility Index (DEMMI): An essential health index for an ageing world. Health Qual Life Outcomes 6: 63. doi:10.1186/1477-7525-6-63.

Dutton RP, Cooper C, Jones A, Leone S, Kramer ME, Scalea TM (2003) Daily multidisciplinary rounds shorten length of stay for trauma patients. Journal of Trauma 55(5): 913-919. doi:10.1097/01.TA.0000093395.34097.56.

Fisher ME, Aristone MN, Young KK, Waechter LE, Landry MD, Taylor LA, Cooper NS (2012) Physiotherapy models of service delivery, staffing, and caseloads: a profile of level I trauma centres across Canada. Physiotherapy Canada 64(4), 377-385. doi:10.3138/ptc.2011-27.

Gabbe BJ, Biostat GD, Lecky FE, Bouamra O, Woodford M, Jenks T, Cameron PA (2011) The effect of an organized trauma system on mortality in major trauma involving serious head injury: a comparison of the United Kingdom and Victoria, Australia. Annals of Surgery 253(1): 138-143. doi:10.1097/ SLA.0b013e3181f6685b.

Gabbe BJ, Simpson PM, Harrison JE, Lyons RA, Ameratunga S, Ponsford J, Cameron PA (2016) Return to work and functional outcomes after major trauma: who recovers, when, and how well? Annals of Surgery 263(4): 623-632. doi:10.1097/SLA.0000000000001564.
Gabbe BJ, Simpson PM, Sutherland AM, Williamson OD, Judson R, Kossmann T, Cameron PA (2008) Functional measures at discharge: Are they useful predictors of longer term outcomes for trauma registries? Annals of Surgery 247(5): 854-859. doi:10.1097/SLA.0b013e3181656d1e.

Gabbe BJ, Simpson PM, Sutherland AM, Wolfe R, Fitzgerald MC, Judson R, Cameron PA (2012) Improved functional outcomes for major trauma patients in a regionalized, inclusive trauma system. Annals of Surgery 255(6): 1009-1015. doi:10.1097/SLA.0b013e31824c4b91.

Khan F, Amatya B, Hoffman K (2012) Systematic review of multidisciplinary rehabilitation in patients with multiple trauma. British Journal of Surgery 99 Suppl 1: 88-96. doi:10.1002/bjs.7776.

Kimmel LA, Edwards ER, Liew SM, Oldmeadow LB, Webb MJ, Holland AE (2012) Rest easy? Is bed rest really necessary after surgical repair of an ankle fracture? Injury 43(6): 766-771. doi:10.1016/j.injury.2011.08.031.

Kimmel LA, Elliott JE, Sayer JM, Holland AE (2016b) Assessing the reliability and validity of a physical therapy functional measurement tool-the modified lowa level of assistance scale-in acute hospital inpatients. Physical Therapy 96(2): 176-182. doi:10.2522/ptj.20140248.

Kimmel LA, Liew SM, Sayer JM, Holland AE (2016a) HIP4Hips (High intensity physiotherapy for hip fractures in the acute hospital setting):a randomised controlled trial. Medical Journal of Australia 205(2): 73-78. doi:10.5694/ mja16.00091.

Lloyd JM, Elsayed S, Majeed A, Kadambande S, Lewis D, Mothukuri R, Kulkarni R (2005) The practice of out-lying patients is dangerous: A multicentre comparison study of nursing care provided for trauma patients. Injury 36(6): 710-713. doi:10.1016/j.injury.2004.11.006.

MacKenzie EJ, Rivara FP, Jurkovich GJ, Nathens AB, Egleston BL, Salkever DS Scharfstein, DO (2008) The impact of trauma-center care on functional outcomes following major lower-limb trauma. Journal of Bone and Joint Surgery (American Volume) 90(1): 101-109. doi:10.2106/JBJS.F.01225.

Ministry of Health New Zealand (2006) Selected morbidity data for publicly funded hospitals 1 July 2002 to 30 June 2003. Wellington, New Zealand. http://www.health.govt.nz/system/files/documents/publications/ morbidity02-03.pdf. [Accessed May, 2016].

Ministry of Health New Zealand. (2015). Mortality and demographic data 2012. Wellington, New Zealand. https://www.health.govt.nz/system/files/ documents/publications/mortality-and-demographic-data-2012-nov15.pdf. [Accessed May, 2016].

Nirula R, Brasel K (2006) Do trauma centers improve functional outcomes: a national trauma databank analysis? Journal of Trauma 61(2): 268-271. doi:10.1097/01.ta.0000230305.36456.4e.

Paice R (2007) An overview of New Zealand's trauma system. Journal of Trauma Nursing 14(4): 211-213.

Palmer CS, Davey TM, Mok MT, McClure RJ, Farrow NC, Gruen RL, Pollard CW (2013) Standardising trauma monitoring: the development of a minimum dataset for trauma registries in Australia and New Zealand. Injury 44(6): 834-841. doi:10.1016/j.injury.2012.11.022.

Pendleton AM, Cannada LK, Guerrero-Bejarano M (2007) Factors affecting length of stay after isolated femoral shaft fractures. Journal of Trauma 62(3): 697-700. doi:10.1097/01.ta.0000197656.82550.39.

Royal Australasian College of Surgeons. (2014). Trauma Verification: The Model Resource Criteria. https://www.surgeons.org/for-hospitals/traumaverification/ [Accessed May, 2016]

Strasser DC, Falconer JA, Herrin JS, Bowen SE, Stevens AB, Uomoto J (2005) Team functioning and patient outcomes in stroke rehabilitation. Archives of Physical Medicine and Rehabilitation 86(3): 403-409. doi:10.1016/j. apmr.2004.04.046

SurveyMonkey Inc. Palo Alto, California, USA. Retrieved from www. surveymonkey.com. 


\section{SURVEY TO PHYSIOTHERAPISTS}

\section{Trauma Service Model of Care}

\section{Q1. What is your trauma service model of care?}

- Dedicated Trauma unit for all trauma patients from admission to discharge

- (Trauma bedcard)

- Trauma admission unit where patients are admitted for a designated time period (up to $24 \mathrm{hrs}$ ) for assessment and then transferred to subspecialty units

- Trauma admissions immediately triaged to subspecialty units (no dedicated trauma unit or bedcard)

- Other (please state)

Q2. Please select the trauma team activities that the trauma physiotherapist (or any physiotherapist) would usually attend:

- Handover

- Ward Rounds

- Unit meetings

- Unit audits

- X-ray rounds

- Education sessions

- Other (please state)

Trauma Physiotherapy

Q3. Do you have a dedicated trauma physiotherapist/s (who is allocated to the trauma unit or who is the main person to treat trauma patients within your model of care)? Yes or No

Q4. What is the referral process for physiotherapy review of trauma patients?

- Blanket referral (all trauma patients seen by physio)

- Referral only

- Self-referred

- Other (please state)

Q5. Please state the grade and speciality of the staff who treat the trauma patients and if possible their full time equivalent (FTE) (e.g: 1.0 FTE, grade 2 orthopaedic, $0.2 \mathrm{FTE}$ grade 3 ICU).

Q6. If you have a dedicated trauma physiotherapist, what areas of the acute hospital do they cover?

- ICU

- Ward

- $\mathrm{ED}$

- Other

- N/A
Q7. What is the service provision for the trauma patients?

- Monday to Friday

- Business hours only

- Early/Late service

- 24 hour cover

- Saturday and Sunday (dedicated to Trauma unit or trauma patients)

- Reduced/priority service

- Business hours only

- Early/Late service

- 24 hour cover

- Other

Q8. Do you use any standardised outcome measures or collect any data on physiotherapy intervention for trauma patients in the acute setting? Yes or No

Q9. If yes:

- What data is collected? Open comment box

- At what time points? Open comment box

- Who collects it? Comment box

- Do you routinely use? Yes or No

If yes, please comment

Q10. Do you use any physiotherapy specific trauma clinical guidelines, pathways or competencies for your patients or physiotherapy staff? Yes or No.

If yes, please give details below.

Q11. Do you run education sessions for physiotherapy staff in trauma management? Yes or No.

If yes, please give details below.

Q12. Are your physiotherapy staff involved in any research related to trauma patients (either as a primary investigator or assisting other staff)? Yes or No.

\section{Q13 Patient Scenarios}

\section{Patient 1}

75 year old female who fell down steps at the shops two days ago.

Injuries sustained:

- C6 fracture managed in a cervical collar for 6 weeks

- $\quad$ Right wrist fracture managed in a plaster of paris (POP) and non-weightbearing (NWB)

Social History (SH): fit, well and independent mobility. Lives alone.

Previous Medical History (PMH)-nil

Her spine has otherwise just been cleared to mobilise. 
Would she be seen by physiotherapy:

- Mon-Fri only?

- Weekend?

After reading the patient's medical notes, reviewing imaging and any relevant other information, what would your first physiotherapy review involve? And how long approximately in minutes would each component take? (Multiple options and time taken for each allowed)

- Full neurological assessment

- Full musculoskeletal assessment

- Full respiratory assessment

- Exercises

- Mobilisation including gait aid provision

- Respiratory intervention

- Discharge planning

- Other- please comment

Patient 2

25 year old male involved in a motor vehicle accident yesterday on a background of alcohol and drug use.

Injuries sustained:

- Perforated right diaphragm requiring a laparotomy and repair

- Fractured right ribs 5-12 with haemopneumothorax managed with an intercostal catheter (ICC)

- Left ankle fracture requiring surgery and an open reduction internal fixation (ORIF), NWB leg for 6 weeks

PMH: Smokes 20 cigarettes/ day and regular recreational drug use.

SH: Usually fully independent and lives at home with his mother.

His pain is well controlled and his respiratory status stable on two litres of oxygen via nasal cannula.

He is now day one post his laparotomy and ankle ORIF. Spine has been cleared.

Would he be seen by physiotherapy:

- Mon-Fri only?

- Weekend?

After reading the patient's medical notes, reviewing imaging and any relevant other information, what would your first physiotherapy review involve? And how long approximately in minutes would each component take? (Multiple options and time taken for each allowed)

- Full neurological assessment

- Full musculoskeletal assessment

- Full respiratory assessment

- Exercises

- Mobilisation including gait aid provision

- Respiratory intervention
- Discharge planning

- Other- please comment

Patient 3

50 year old female after a motorbike accident four days ago.

Injuries sustained:

- Left mid-shaft femur fracture requiring an intramedullary nail four days ago, NWB on leg

- L3 burst fracture requiring ORIF three days ago, no neurological involvement and no post-op position or mobility restrictions

PMH- nil

$\mathrm{SH}$ - lives with supportive husband in a single level house. No steps to access.

So far she has managed just a transfer to sit out of bed with assistance of 2 physiotherapists.

Would she been seen by physiotherapy:

- Mon-Fri only?

- Weekend?

After reading the patient's medical notes, reviewing imaging and any relevant other information, what would your physiotherapy review involve today (day four post admission)? And how long approximately in minutes would each component take? (Multiple options and time taken for each allowed)

- Full neurological assessment

- Full musculoskeletal assessment

- Full respiratory assessment

- Exercises

- Mobilisation including gait aid provision

- Respiratory intervention

- Discharge planning

- Other- please comment

Patient 4

80 year old male after a fall at home three days ago onto his coffee table.

Injuries sustained:

- Right pubic rami fracture: conservative management, weightbear as tolerated

- Five right rib fractures (with radiological and clinical flail) and associated haemothorax and ICC

PMH- Atrial fibrillation, osteoporosis, obese

$\mathrm{SH}$ - usually lives alone but does require a four wheeled frame to walk outdoors further than 100 metres.

$\mathrm{He}$ is currently requiring humidified oxygen (approximate $\mathrm{FiO} 2$ of $40 \%$ ) via a face mask for Sp02 of $93 \%$ and has only managed to sit out of bed once using a gutter frame and assistance of two physiotherapists. 
He is limited by pain and also has evidence of secretion retention.

Would he been seen by physiotherapy:

- Mon-Fri only?

- Weekend?

After reading the patient's medical notes, reviewing imaging and any relevant other information, what would your physiotherapy review involve today (day 3 post admission?) And how long approximately in minutes would each component take? (Multiple options and time taken for each allowed)

- Full neurological assessment

- Full musculoskeletal assessment

- Full respiratory assessment

- Exercises

- Mobilisation including gait aid provision

- Respiratory intervention

- Discharge planning

- Other- please comment

Q14. Would you be interested in being part of future collaborative physiotherapy research? Yes or No

Q15. Would you be interested in being part of a trauma network aimed at supporting and sharing knowledge and skills for those working with trauma patients? Yes or No

Q16. Would you like to be acknowledged in any publications or presentations? Yes or No

Thank you for your time completing this survey. Please do not hesitate to contact me if you have any questions regarding this information.

\section{Sara Calthorpe}

Senior Trauma Physiotherapist

The Alfred

Melbourne, Victoria, Australia 